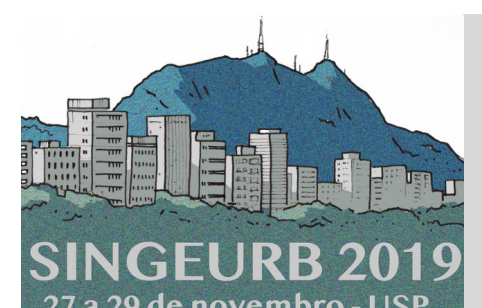

II Simpósio Nacional de Gestão e Engenharia Urbana

ABORDAGEM SISTÊMICA, ESCALAS E INTERSETORIALIDADE: DESAFIOS E POTENCIAIS DO DESENVOLVIMENTO URBANO SUSTENTÁVEL

\title{
Ecologia Social aplicada ao mundo real: Projetos de urbanização em ocupações de áreas de proteção de mananciais em São Bernardo Do Campo
}

\section{Social Ecology applied to the real world: Urbanization projects in occupations of water supplies areas in São Bernardo Do Campo}

\author{
Silva, Ananda Ramos'; Ferrara, Luciana Nicolau2; \\ 1 Universidade Federal do ABC, ananda.r@aluno.ufabc.edu.br \\ 2 Universidade Federal do ABC, luciana.ferrara@ufabc.edu.br
}

\begin{abstract}
RESUMO
A região do $A B C$ paulista apresenta conflitos sociais e urbanos relacionados às características geográficas e legais de proteção ambiental que incidem sobre o território inserido na área de proteção e recuperação de mananciais. A região possui uma trajetória de políticas habitacionais desenvolvidas pelos municípios, que englobam novos desafios para a execução de projetos de urbanização. No contexto das áreas de mananciais ocupadas por assentamentos precários, a principal questão é considerar maneiras de urbanizar que busquem a qualificação ambiental, a implementação de infraestruturas, a melhoria da condição habitacional e a minimização de impactos. Este artigo visa abordar como as questões sociais e ambientais estão sendo conciliadas no âmbito de projetos de intervenção, mediante o estudo do projeto para as comunidades Capelinha e Cocaia em São Bernardo 'do Campo. Além da análise do projeto, foi realizada entrevista com arquiteto responsável e visita de campo acompanhada por moradores. Identificam-se como resultados as principais dificuldades na elaboração e execução do projeto, a metodologia adotada, suas diretrizes básicas e as mudanças na qualidade de vida da população local. A análise é realizada à luz da Ecologia Social, que traz uma perspectiva de compreensão sobre o meio ambiente articulando aspectos naturais, sociais, econômicos e culturais.
\end{abstract}

Palavras-chave: Urbanização, Proteção ambiental, Moradia, Participação social.

\begin{abstract}
The $A B C$ region presents social and urban conflicts related to the geographic and legal environmental characteristics that affect the territory included in the protection and recovery areas for water supplies. The region also presents a trajectory of housing policies developed by the municipalities, which encompasses new challenges for projects of slum upgrading.
\end{abstract}

1 SILVA, Ananda Ramos; Ferrara, Luciana Nicolau. Ecologia Social aplicada ao mundo real: Projetos de urbanização em ocupações de áreas de proteção de mananciais em São Bernardo Do Campo. In: II SIMPÓSIO NACIONAL DE GESTÃO E ENGENHARIA URBANA: SINGEURB, 2019, São Paulo. Anais... Porto Alegre: ANTAC, 2019. 
In the context of water supply areas occupied by precarious settlements, the main issue is to consider ways to urbanize with environmental qualification, implementation of infrastructure, improving housing conditions and minimization of impacts. This article addresses how social and environmental issues are being reconciled in the context of intervention projects, by studying the project for the Capelinha and Cocaia communities in São Bernardo do Campo. Besides the project analysis, an interview with responsible architect and a site visit accompanied by residents were conducted. The main elaboration and execution difficulties of the project, the methodology adopted, its basic guidelines and the changes in life quality of the local population are identified as results. The analysis is based in the light of Social Ecology, which brings a perspective in which the environment is understood through natural, social, economic and cultural aspects.

Keywords: Urbanization, Environmental protection, Housing, Social participation.

\section{INTRODUÇÃO}

A "industrialização com baixos salários" iniciada na década de 1930, somada às políticas públicas habitacionais insuficientes acarretaram que as únicas alternativas de moradia da classe operária fossem as favelas, as ocupações ilegais, a autoconstrução e os demais tipos de habitações irregulares, que frequentemente encontram-se em áreas impróprias para construção como as áreas de proteção ambiental (MARICATO, 1996).

Em relação ao ABC paulista, sua ocupação intensificou-se durante a década de 1950 devido à intensa expansão demográfica proveniente da migração de mão de obra em busca de trabalho na indústria automobilística que se instituía na região (MOMM-SCHULT et al., 2014).

A região apresenta embates relacionados às características geográficas e legais de proteção ambiental que incidem sobre o território e à história da política de urbanização de favelas desenvolvida pelos municípios que abrange novos desafios para a execução de projetos de urbanização e habitação (DENALDI, et al., 2016). É recente a consideração da dimensão ambiental de modo mais explícito e amplo na urbanização de favelas, que inicialmente priorizava a solução de saneamento.

Entre os anos 1960 e 1970, houve extensos debates em torno de temas ecológicos (LAGO e PÁDUA, 1984). A ecologia, como conhecimento que nasce da biologia, passa a ser considerada de forma mais ampla, na interação entre sociedade e meio ambiente. Neste período, a Ecologia Social também entrou em discussão trazendo a ideia de que os problemas ecológicos estão enraizados aos problemas sociais (BOOKCHIN, 2010). Segundo Maciel e Ritter (2005), a Ecologia Social baseia-se nos campos da Ecologia Humana, do Desenvolvimento Endógeno, do Eco desenvolvimento e do Desenvolvimento Sustentável, assim, "A partir da perspectiva da Ecologia Social, o meio ambiente é compreendido na sua totalidade, incluindo aspectos sociais, econômicos, culturais e naturais" (MACIEL e RITTER, 2005, p. 82). Contudo, essa perspectiva nem sempre é obtida quando se trata do contexto da urbanização desigual.

O conflito entre direito à moradia e proteção ambiental é explícito no contexto das áreas de mananciais ocupadas por assentamentos precários, onde, desde os anos 1990, a principal questão é considerar maneiras de urbanização que busquem, o máximo possível, preservar ou restabelecer condições para que um manancial se mantenha adequado exercendo sua função como tal e de modo a conciliar a garantia do direito à moradia (FERRARA E MARTINS, 2014).

Portanto, é necessário conhecer em maior profundidade esse tipo de assentamento para compreender suas necessidades e papéis tanto ecológicos quanto sociais. Assim, este estudo visa abordar como as questões habitacionais e ambientais estão sendo conciliadas nos assentamentos Capelinha e Cocaia situados em uma área de manancial no município de São Bernardo do Campo mediante entrevista com um dos responsáveis pelo projeto e visita aos assentamentos utilizando o conceito de Ecologia Social para avaliar os resultados do projeto de urbanização integrado. 


\section{PROJETO DE URBANIZAÇÃO INTEGRADA CAPELINHA/COCAIA}

O projeto de urbanização integrada dos assentamentos Capelinha/Cocaia foi elaborado pela Peabiru - Trabalhos Comunitários e Ambientais, uma ONG de Assistência Técnica fundada em 1993. Os recursos para elaboração do projeto foram providos mediante uma parceria entre a prefeitura de São Bernardo do Campo e o governo federal através do Programa de Aceleração do Crescimento (PAC) Urbanização de Assentamentos Precários. A prefeitura realizou o levantamento socioeconômico e incumbiu-se da regularização fundiária enquanto a Peabiru responsabilizou-se pela assistência técnica e elaboração do projeto. Durante o processo a população atingida foi consultada mediante assembleias (PEABIRU, 2011; HODAPP, 2019 e SILVA, 2013).

O objetivo principal do projeto foi integrar o espaço construído às áreas de preservação ambiental em seu entorno, admitindo as seguintes diretrizes principais: prover o núcleo de infraestrutura; assegurar habitação de qualidade a todos; e aprimorar as condições ambientais da área (FERRARA, 2013). O projeto integrado dos assentamentos passou por licenciamento ambiental na Cetesb como um único PRIS (Programa de Recuperação de Interesse Social), conforme rege a Lei Específica da APRM Billings. Os assentamentos estão distantes e isolados da mancha urbana consolidada do município, em meio a áreas vegetadas.

Figura 1 - Localização do assentamento Capelinha

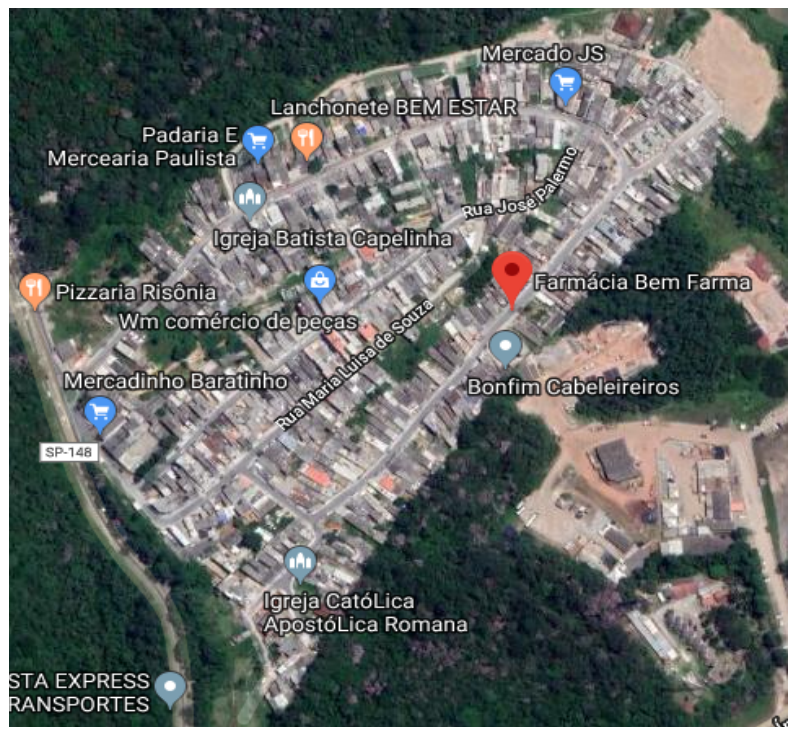

Fonte: Google Satélite, 2019

Figura 2 - Localização do assentamento Cocaia

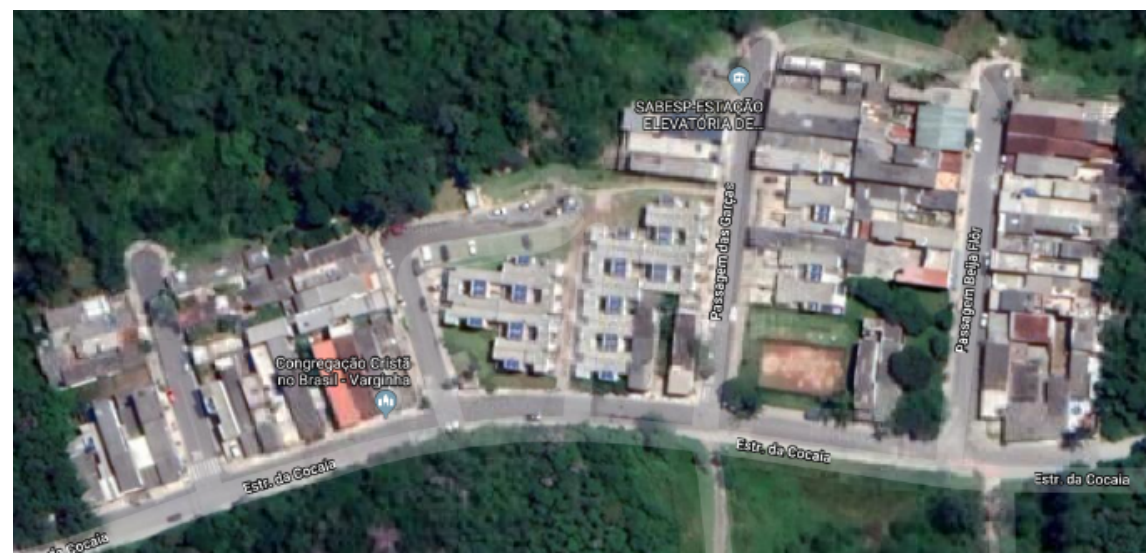

Fonte: Google Satélite, 2019 


\subsection{Principais intervenções}

- Remoções, reassentamentos e realocações

A solução habitacional articulou os assentamentos. Os lotes desocupados do Cocaia foram integrados para o reassentamento de moradias removidas de áreas de risco e preservação permanente no loteamento Capelinha visando melhorar a condição de infraestrutura pública do Cocaia e de qualificação urbana e ambiental do Capelinha (FERRARA, 2013).

A proposta de inserção de novas unidades habitacionais concilia-se à forma de ocupação tradicional dos assentamentos removendo situações de maior precariedade e risco e inserindo novas unidades de reassentamento com o padrão já instituído, não reproduzindo as tipologias de edifícios de interesse social comumente aplicadas indistintamente em projetos de intervenção, proporcionando um ganho na qualidade habitacional: o projeto visou casas sobrepostas, como sobrados (FERRARA, 2013).

Figura 3 - Unidades habitacionais construídas pelo projeto

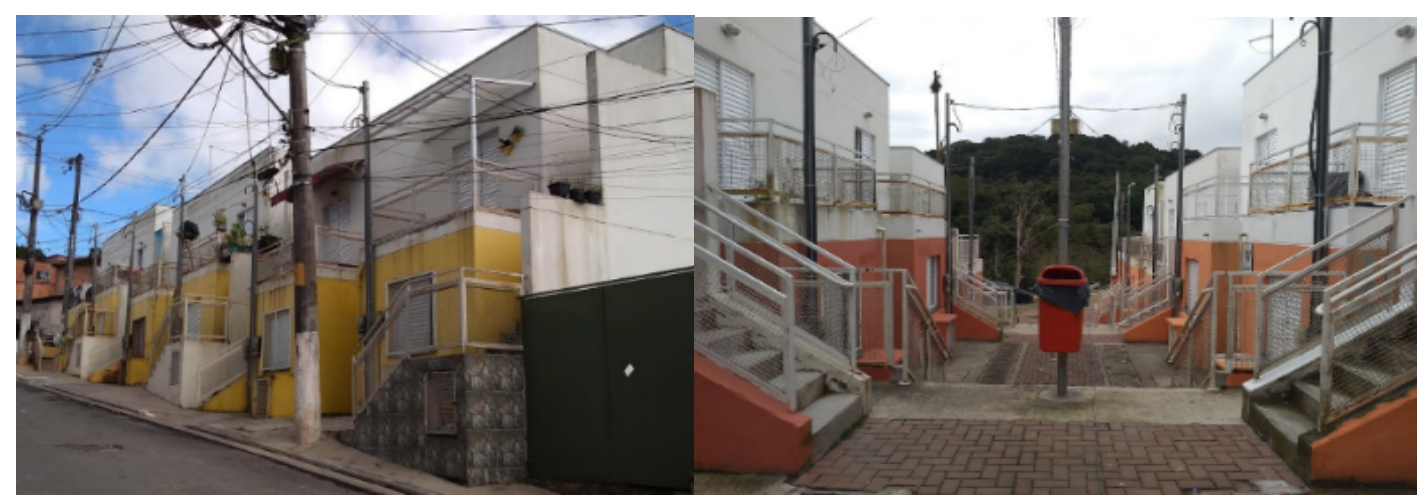

Fonte: As autoras, 2019

Na revisão do projeto em 2015, foram estimadas 218 remoções e a construção de 194 novas unidades (HODAPP, 2019).

\section{- Saneamento}

A SABESP executou o projeto e a obra de rede de água em 2012, que incluiu: captação em um poço próximo ao Capelinha, tratamento de água em uma estação compacta (ETA), reservação, bombeamento por booster, adução até a área do assentamento e distribuição (FERRARA, 2013).

Figura 4 - Poço da Sabesp

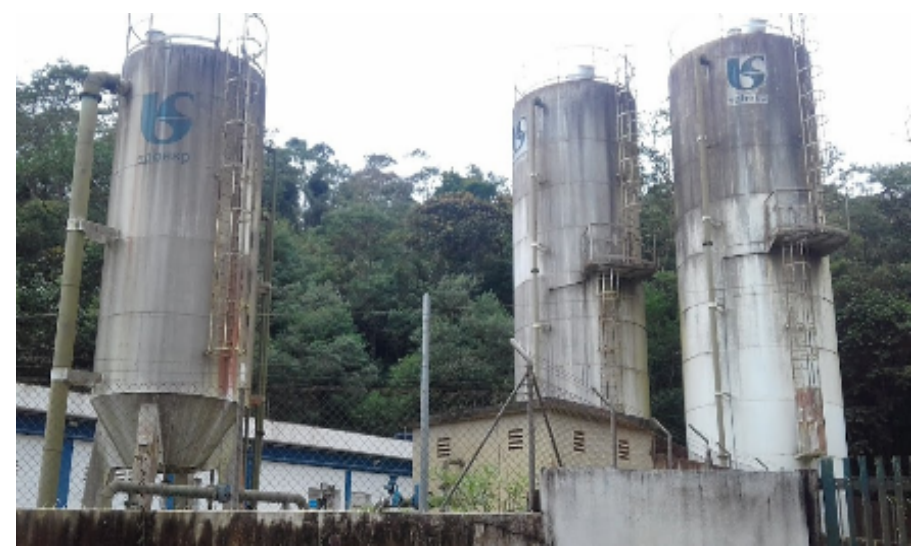

Fonte: As autoras, 2019

Ainda houve a implantação de uma pequena estação elevatória de esgotos (EEE) em cada assentamento (HODAPP, 2019 e FERRARA, 2013). 
Figura 5 - Estações Elevatórias de Esgoto dos assentamentos

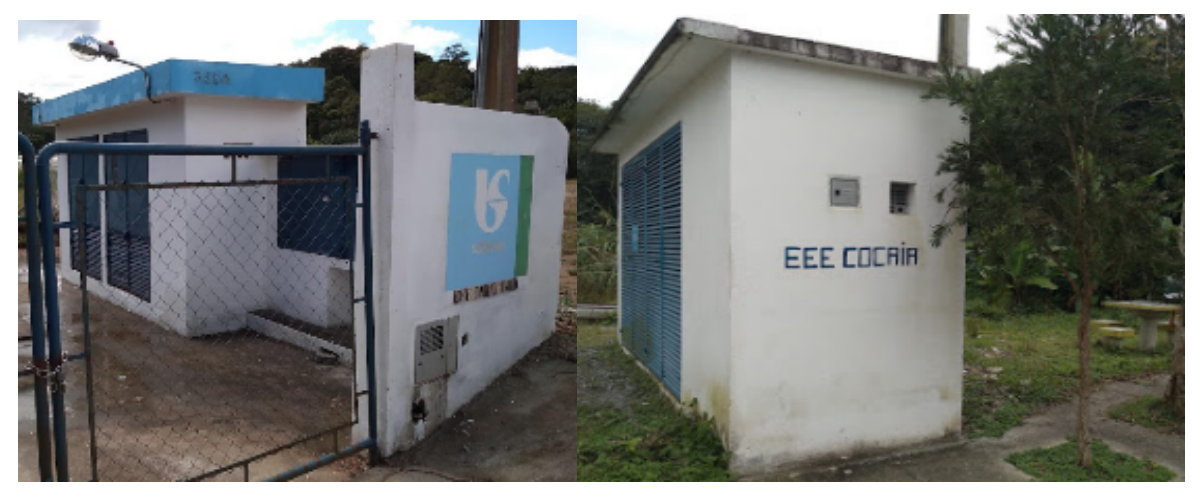

Fonte: As autoras, 2019

O projeto de infraestrutura foi compatibilizado com o projeto de urbanização e abertura do viário. Anteriormente, o acesso à água era feito por caminhão pipa pela prefeitura, e não havia rede de coleta de esgoto.

- Recuperação ambiental e demandas da população

A proposta previu a recuperação de um córrego presente no Capelinha através de um parque linear e de uma nascente próxima à estrada que dá acesso ao loteamento (HODAPP, 2019). Na visita de campo, observou-se que o projeto não foi totalmente implantado. As águas do córrego estão aparentemente translúcidas, mas ainda há esgoto a céu aberto despejado de casas próximas, que não foram removidas da APP.

Figura 6 - Esgoto a céu aberto despejado em córrego no Capelinha

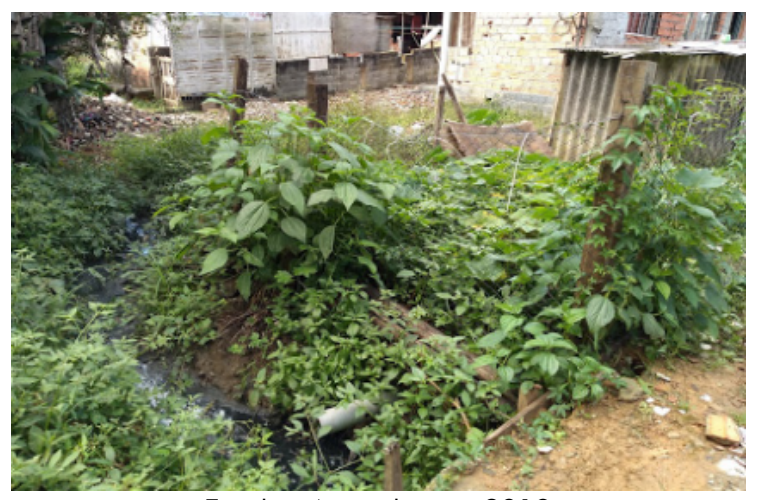

Fonte: As autoras, 2019

No Cocaia, o córrego foi recuperado através de um pequeno parque linear.

Figura 7 - Córrego recuperado no Cocaia

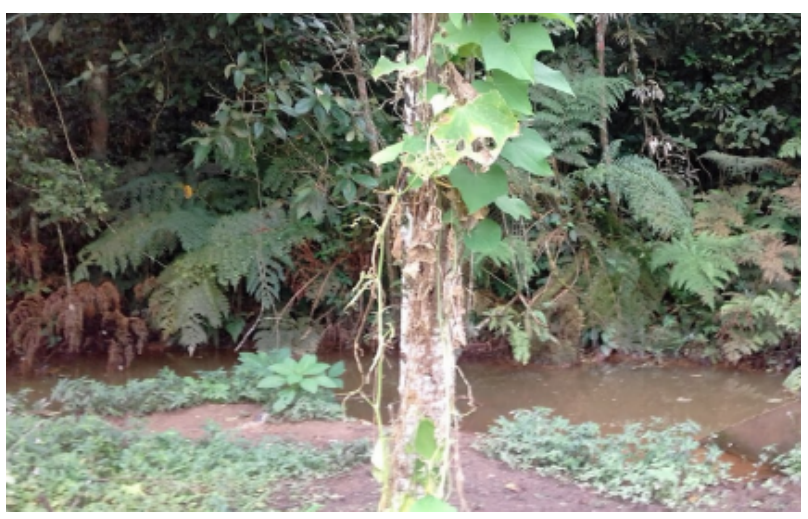

Fonte: As autoras, 2019

A fim de evitar novas edificações e ampliar a área permeável, as novas unidades habitacionais contam com um jardim comum entre as famílias (HODAPP, 2019). 
Figura 8 - Jardins em novas unidades habitacionais no Cocaia

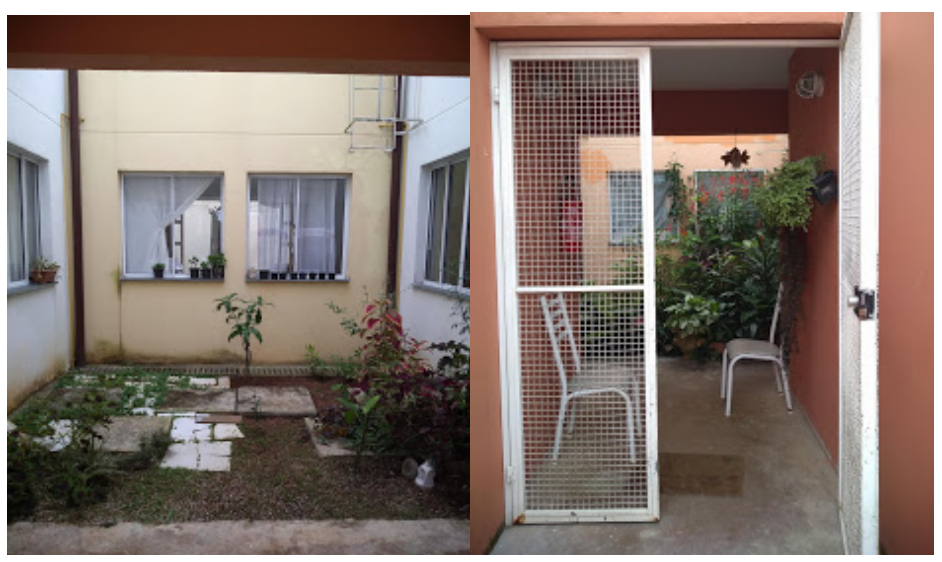

Fonte: As autoras, 2019

Em relação às demandas da população, através das audiências públicas, foram identificadas demandas por áreas livres e de lazer (HODAPP, 2019).

Figura 9 - Áreas livres e de lazer no Cocaia

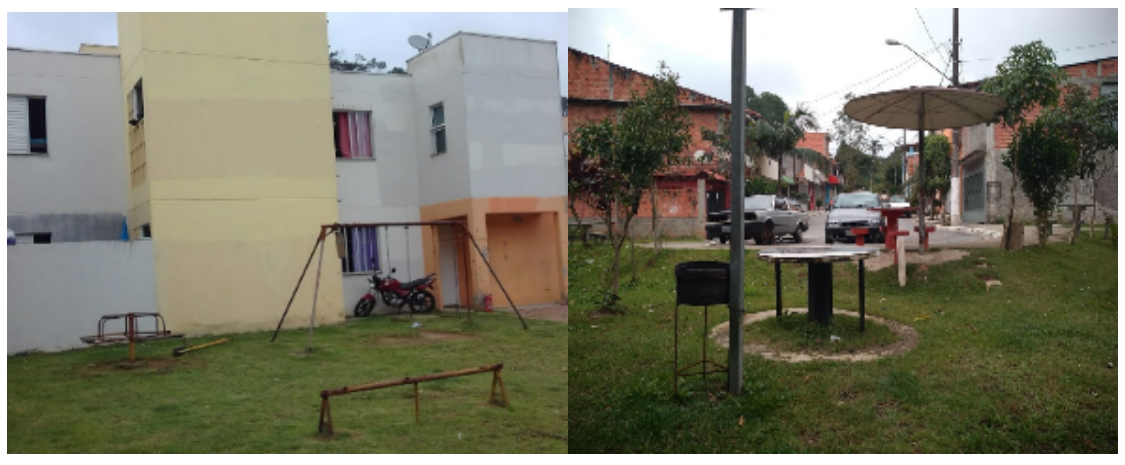

Fonte: As autoras, 2019

- Execução do projeto

O projeto técnico e social para o licenciamento ambiental foi concluído em 2011 e as obras foram iniciadas em 2013. Entretanto, devido à paralisação das obras em 2016 o projeto ainda está inconcluso. A seguir, há um quadro resumindo a execução do projeto.

Quadro 1 - Resumo dos principais acontecimentos na execução do projeto

\begin{tabular}{|c|c|c|c|c|c|}
\hline $2010-2011$ & 2013 & 2015 & 2016 & 2018 & 2019 \\
\hline \multirow{3}{*}{$\begin{array}{c}\text { Elaboração } \\
\text { do projeto } \\
\text { técnico e } \\
\text { social pela } \\
\text { Peabiru TCA. }\end{array}$} & \multirow{3}{*}{$\begin{array}{l}\text { Dezembro } \\
\text { Início das } \\
\text { obras. }\end{array}$} & \multirow{3}{*}{$\begin{array}{l}\text { Revisão } \\
\text { do } \\
\text { projeto. }\end{array}$} & $\begin{array}{l}\text { Maio } \\
\text { Entrega de } 52 \text { moradias } \\
\quad \text { no Cocaia. }\end{array}$ & \multirow{3}{*}{$\begin{array}{l}\text { Março } \\
\text { Abertura } \\
\text { de edital } \\
\text { para a } \\
\text { retomada } \\
\text { das obras. }\end{array}$} & \multirow{3}{*}{$\begin{array}{l}\text { Abril } \\
\text { Assinatura da } \\
\text { ordem de serviçc } \\
\text { para retomada } \in \\
\text { término das } \\
\text { unidades } \\
\text { habitacionais no } \\
\text { Capelinha. }\end{array}$} \\
\hline & & & $\begin{array}{l}\text { Março } \\
\text { Entrega de } 12 \text { moradias } \\
\quad \text { no Capelinha. }\end{array}$ & & \\
\hline & & & $\begin{array}{l}\text { Dezembro } \\
\text { Paralisação das obras } \\
\text { no Capelinha. }\end{array}$ & & \\
\hline
\end{tabular}

Fonte: PEABIRU, 2011; PROIETI, 2013; SILVA, 2013; DORADOR, 2016; BORBA, 2016; MOTODA e RIBEIRO, 2017; MACÁRIO, 2018; HODAPP, 2019; DOMICIANO, 2019 


\section{METODOLOGIA}

- Coleta dos dados

A coleta dos dados foi efetuada mediante uma entrevista semiestruturada, ou seja, com perguntas previamente formuladas que podem ser modificadas segundo as declarações do entrevistado (MINAYO, 2002). O entrevistado foi o arquiteto e urbanista Alexandre Hodapp, um dos responsáveis pelo projeto, que concedeu a entrevista em 27 de fevereiro de 2019.

Uma visita de campo acompanhada por moradores foi realizada em ambos os assentamentos em 29 de abril de 2019. Além de pesquisa bibliográfica e pesquisa documental sobre análise do projeto de intervenção mediante imagens cedidas pela Peabiru.

- Análise dos dados

Os dados coletados na entrevista foram analisados através da técnica Análise de Conteúdos, que tem duas funções: i) verificar as hipóteses e/ou questões estabelecidas durante a fase exploratória da pesquisa e ii) desvendar o que está por trás do que foi relatado, indo além das aparências do que está sendo declarado (MINAYO, 2002).

\section{RESULTADOS E DISCUSSÃO}

Na visita constatou-se que as obras de urbanização no Cocaia foram concluídas. Contudo, cerca de $40 \%$ das obras do Capelinha estão inconclusas, principalmente, relacionadas às novas unidades habitacionais.

Figura 10 - Unidades habitacionais inconclusas no Capelinha

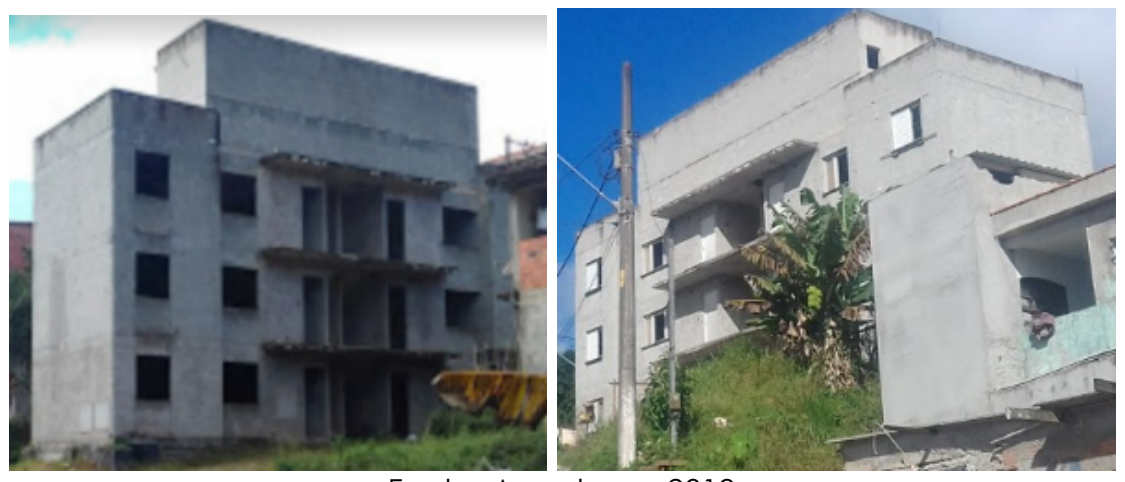

Fonte: As autoras, 2019

O quadro 2 resume as principais informações obtidas através da entrevista com o Alexandre Hodapp e observadas na visita aos locais.

Quadro 2 - Resumo da entrevista com Alexandre Hodapp e do observado na visita

\begin{tabular}{|c|l|}
\hline $\begin{array}{c}\text { Principais } \\
\text { dificuldades }\end{array}$ & $\begin{array}{l}\text { - Realização do levantamento altimétrico devido à ligação entre as residências; } \\
\text { - Flexibilização do projeto: a dinâmica da área exigia atualizações constantes } \\
\text { para que o projeto se adequasse às mudanças locais. }\end{array}$ \\
\hline Diretriz principal & - Manutenção de todos os moradores na área de intervenção. \\
\hline Metodologia & $\begin{array}{l}\text { - Classificação das residências por nível de precariedade. } \\
\text { - Consideração da legislação ambiental e de mananciais. }\end{array}$ \\
\hline $\begin{array}{c}\text { Principais } \\
\text { impactos positivos }\end{array}$ & $\begin{array}{l}\text { - Implementação de redes de água e coleta de esgoto; } \\
\text { - Pavimentação das ruas; } \\
\text { - Criação de linhas e pontos de ônibus; } \\
\text {-Implantação de parque linear para recuperação de córrego. }\end{array}$ \\
\hline Participação social & - Remoções foram repensadas por reivindicação dos moradores; \\
\hline $\begin{array}{c}\text { Manutenção das } \\
\text { intervenções }\end{array}$ & $\begin{array}{l}\text { - As tipologias das moradias implantadas visam a manutenção das intervenções; } \\
\text { - Para que os moradores obtivessem a titulação da moradia era necessária a } \\
\text { manutenção da APP. }\end{array}$ \\
\hline
\end{tabular}




\section{CONCLUSÕES}

A ocupação de áreas protegidas e/ou ambientalmente sensíveis é uma consequência direta do histórico de urbanização desigual e segregação social e espacial do meio urbano brasileiro. A Ecologia Social aponta que é inviável tratar problemas ambientais e sociais isoladamente e estabelece a necessidade de enxergar o meio ambiente a partir de aspectos ambientais, sociais e econômicos de modo articulado.

O caso dos assentamentos Capelinha e Cocaia evidencia que a melhoria da qualidade de vida da população pode auxiliar na preservação ambiental de modo a ser possível conciliar as funções sociais e ecológicas de um local. A requalificação habitacional aliada ao fornecimento de saneamento básico e implantação de áreas vegetadas livres e de lazer podem aprimorar a qualidade do manancial proporcionando a diminuição da sua polvição.

\section{AGRADECIMENTOS}

Ao arquiteto e urbanista Alexandre Hodapp por ter concedido seu tempo à elaboração desta pesquisa e à Universidade Federal do $A B C$ (UFABC) pela oportunidade de desenvolvimento científico através do Programa de Iniciação Científica (PIC).

\section{REFERÊNCIAS}

BOOKCHIN, M. Ecologia social e outros ensaios. Organização e revisão da tradução de Mauro José Cavalcanti. Rio de Janeiro: Achiamé, 2010, p. 127-130.

BORBA, M. Prefeito entrega 52 moradias no assentamento Capelinha/Cocaia. Prefeitura Municipal de São Bernardo do Campo, 2016. Disponível em:

<http://www.saobernardo.sp.gov.br/home/-

/asset_publisher/YVwaH6UqAMbt/content/prefeito-entrega-52-moradias-no-assentamentocapelinha-cocaia-no-sabado/maximized>. Acesso em: 23 nov. 2018.

DENALDI, R.; FERRARA, L. N.; SILVA, P. H. A dimensão ambiental da intervenção de favelas: o caso do ABC paulista. In: Seminário URBFAVELAS 2016, 2016. Disponível em: <http://www.sisgeenco.com.br/sistema/urbfavelas/anais2016/ARQUIVOS/GT1-151-13220161013225422.pdf>. Acesso em: 19 mar. 2018.

DOMICIANO, H. Prefeitura de São Bernardo garante retomada de unidades habitacionais no bairro Capelinha. Prefeitura Municipal de São Bernardo do Campo, 2019. Disponível em: <https://bit.ly/2HOVn9i>. Acesso em: 25 mai. 2019.

DORADOR, M. Prefeito entrega 52 moradias no assentamento Capelinha/Cocaia. Prefeito entrega moradias do Projeto de Urbanização Integrada do Capelinha. Prefeitura Municipal de São Bernardo do Campo, 2016. Disponível em:

<http://www.saobernardo.sp.gov.br/home//asset_publisher/YVwaH6UqAMbt/content/prefeito-entrega-moradias-do-projeto-deurbanizacao-integrada-do-capelinha/maximized>. Acesso em: 23 nov. 2018.

FERRARA, L. N. Urbanização da natureza: da autoprovisão de infraestruturas aos projetos de recuperação ambiental nos mananciais do sul da metrópole paulistana. 2013. Tese (Doutorado em Tecnologia da Arquitetura) - Faculdade de Arquitetura e Urbanismo, Universidade de São Paulo, São Paulo, 2013. doi:10.11606/T.16.2013.tde-25092013-110858. Acesso em: 19 mar. 2018.

FERRARA, L. N.; MARTINS, M. L. R. R. O desenho ambiental da infraestrutura urbana: princípios de projeto para regularização de interesse social. In: III Encontro da Associação Nacional de Pesquisa e Pós-Graduação em Arquitetura e Urbanismo - III 
ENANPARQ, 2014. Disponível em:

http://www.anparq.org.br/dvdenanparq3/htm/Artigos/ST/ST-AS-002-3-FERRARA.MARTINS.pdf. Acesso em: 24 mar. 2018.

HODAPP, A. Entrevista concedida a Ananda Ramos da Silva e Luciana Nicolau Ferrara. São Paulo, 27 fev. 2019.

LAGO, A.; PÁDUA, J. A. O que é Ecologia? São Paulo: Abril Cultural: Brasiliense, 1985. p. 85106.

MACÁRIO, D. Urbanização do Cocaia e Capelinha será retomada. Diário do Grande ABC, 2018. Disponível em: <https://www.dgabc.com.br/Noticia/2866794/urbanizacao-do-cocaiae-capelinha-sera-retomada>. Acesso em: 23 nov. 2018.

MACIEL, T. B.; RITTER, P. Desenvolvimento sustentável, diversidade e novas tecnologias: a relação com a ecologia social. Porto Alegre: PSICO, PUCRS, v. 36, n. 1, p. 81-87, jan./abr. 2005. Disponível em: <http://revistaseletronicas.pucrs.br/ojs/index.php/revistapsico/article/vie

wFile/1378/1078>. Acesso em: 05 abr. 2018.

MARICATO, E. T. M. Metrópole na periferia do capitalismo: ilegalidade, desigualdade e violência. São Paulo: Editora Hucitec, $1^{a}$ ed., 1996, p. 39-49.

MINAYO, M. C. de L. (Org.) Pesquisa social: teoria, método e criatividade. Petrópolis: Vozes, $21^{\mathrm{a} e d .} 2002$.

MOMM-SCHULT, S. I.; FREITAS, S. R.; PASSARELLI, S. H. Uso urbano e serviços ecossistêmicos em áreas protegidas: o caso do Parque Guaraciaba em Santo André (SP). In: Seminário Nacional sobre o Tratamento de Áreas de Preservação Permanente em Meio Urbano e Restrições. Ambientais ao Parcelamento do Solo - APPURBANA 2014, 2014. Disponível em: <http://anpur.org.br/app-urbana-2014/anais/ARQUIVOS/GT2-145-87-20140527172841.pdf>. Acesso em: 22 mar. 2018.

MOTODA, E; RIBEIRO, T . Obra habitacional no Riacho Grande está atrasada há mais de um ano. Rudge Ramos online - Universidade Metodista de São Paulo, 2017. Disponível em: <http://www.metodista.br/rronline/noticias/cidades/2017-1/obra-habitacional-no-riachogrande-esta-parada-ha-mais-de-um-ano>. Acesso em: 23 nov. 2018.

PEABIRU. Capelinha e Cocaia, 2011. Disponível em:

<http://www.rutca.org.br/?painel_projetos /?painel_projetos=capelinha-cocaia>. Acesso em: 23 nov. 2018.

PROIETI, C. Urbanização de Cocaia e Capelinha é iniciada. Diário do Grande ABC, 2013. Disponível em: <https://www.dgabc.com.br/Noticia/499211/urbanizacao-dos-nucleoscocaia-e-capelinha-e-iniciada-em-s-bernardo>. Acesso em: 23 nov. 2018.

SILVA, C. Prefeito autoriza início da urbanização integrada no Capelinha e Cocaia.

Prefeitura Municipal de São Bernardo do Campo, 2013. Disponível em:

<https://bit.ly/2voYFJj>. Acesso em: 23 nov. 2018. 